\title{
Why do right-wing adherents engage in more animal exploitation and meat
} consumption?

\author{
Kristof Dhont $^{\mathrm{a}}$ \& Gordon Hodson ${ }^{\mathrm{b}}$
}

Paper published in Personality and Individual Differences

Dhont, K., \& Hodson, G. (2014). Why do right-wing adherents engage in more animal exploitation and meat consumption? Personality and Individual Differences, 64, 12-17.

${ }^{a}$ Corresponding Author; Department of Developmental, Personality and Social Psychology, Ghent University, Belgium. Address: Henri Dunantlaan 2, B-9000, Ghent, Belgium E-mail: Kristof.Dhont@UGent.be; Tel: +3292646424. Kristof Dhont is a post-doctoral researcher supported by the Research Foundation - Flanders (FWO, Belgium).

${ }^{\mathrm{b}}$ Department of Psychology, Brock University, Canada. Address: 500 Glenridge Ave., St. Catharines, Ontario, Canada L2S 3A1. E-mail: ghodson@brocku.ca 


\begin{abstract}
Despite the well-documented implications of right-wing ideological dispositions for human intergroup relations, surprisingly little is understood about the implications for humananimal relations. We investigate why right-wing ideologies - social dominance orientation (SDO) and right-wing authoritarianism (RWA) - positively predict attitudes toward animal exploitation and meat consumption. Two survey studies conducted in heterogeneous community samples (Study 1, $N=260$; Study 2, $N=489$ ) demonstrated that right-wing ideologies predict greater acceptance of animal exploitation and more meat consumption through two explaining mechanisms: (a) perceived threat from non-exploitive ideologies to the dominant carnist ideology (for both SDO and RWA) and (b) belief in human superiority over animals (for SDO). These findings hold after controlling for hedonistic pleasure from eating meat. Right-wing adherents do not simply consume more animals because they enjoy the taste of meat, but because doing so supports dominance ideologies and resistance to cultural change. Psychological parallels between human intergroup relations and humananimal relations are considered.
\end{abstract}

Key words: right-wing ideology; meat consumption; animal exploitation; attitudes 


\section{Why Do Right-Wing Adherents Engage in More Animal Exploitation and Meat Consumption?}

"The animals of the world exist for their own reasons. They were not made for humans any more than black people were created for whites, or women for men" (Alice Walker)

\section{Introduction}

Scholars have identified two primary dispositional dimensions underlying right-wing ideology (e.g., Altemeyer, 1998; Duckitt, 2001). Right-Wing Authoritarianism (RWA, Altemeyer, 1981) pertains to the submissive dimension, and reflects cultural traditionalism, uncritical submission to authorities, and aggressiveness towards norm violators. Social Dominance Orientation (SDO, Pratto, Sidanius, Stallworth, \& Malle, 1994) is a typical indicator of the dominance dimension of ideology, and is operationalized as a generalized desire for group-based dominance and inequality among social groups (Pratto et al., 1994, Sidanius \& Pratto, 1999). Numerous studies have indicated that RWA and SDO are both strong and unique predictors of outgroup prejudice, and related justifications for discrimination and exploitation of outgroup members across multiple domains, including racial and ethnic prejudice and sexism (e.g., Altemeyer, 1998; Duckitt, 2001; Hodson \& Busseri, 2012; Roets, Van Hiel, \& Dhont, 2012; Sidanius \& Pratto 1999).

Despite the well-documented implications of individual differences in ideology with regard to reactions toward human outgroups, surprisingly little is understood about the implications for non-human animals. As Walker's poignant observation clarifies, many biases, including those involving non-human animals, are rooted in common ideological belief systems and show psychological parallels (see Costello \& Hodson, 2010, in press; Hodson \& Costello, 2012; Jackson, 2011; Plous, 2003).

Few studies have investigated relations between social-ideological orientations and exploitative attitudes and behaviors toward animals. Yet existing evidence reveals positive 
associations between right-wing ideologies such as RWA and SDO, on the one hand, and attitudes toward the exploitation of animals as objects for human benefit (e.g., animal testing, fur industry, rodeos), and direct behavioral expression of dominant belief systems regarding human-animal relations such as meat consumption, on the other. Indeed, those endorsing right-wing attitudes and values are more likely to support and engage in animal exploitation and to self-identify as meat-eaters (e.g., Allen, Wilson, Ng, \& Dunne, 2000; Dietz, Frisch, Kalof, Stern, \& Guagnano, 1995; Hyers, 2006). Likewise, right-wing adherents tend to consume more meat in daily life (e.g., Allen et al., 2000; Allen \& Ng, 2003; Ruby, 2012).

To date, however, it remains unclear why people scoring higher (vs. lower) on rightwing social attitudes are more accepting of animal exploitation and eat more meat. We propose two psychological mechanisms potentially accounting for these relations. Building on both human intergroup and human-animal relations literatures, we argue that right-wing adherents would not be more accepting of animal exploitation or eat more meat if not for their (a) sense of threat from increasingly popular non-exploitive ideologies toward animals (i.e., veg(etari)anism); and (b) human supremacy beliefs.

\subsection{Vegetarianism Threat and Human Supremacy Beliefs}

Animal exploitation and meat consumption are arguably part of the dominant ideological system 'carnism', prescribing norms and beliefs about animal treatment (Joy, 2010). Particularly in Western countries, however, people are increasingly reducing meat consumption, becoming vegetarian, or endorsing non-exploitive ideologies toward animals (i.e., veg(etari)anism) (Ruby, 2012). This change may be experienced as a threat to traditional norms and dominant carnist ideologies. From an intergroup perspective, Integrated Threat Theory (Stephan \& Stephan, 2000) posits that perceived outgroup threats are fundamental antecedents to negative outgroup attitudes, and can pertain to threats to dominant ingroup's norms and values, in addition to threats to ideological, political, and economic power 
(Stephan \& Renfro, 2002). Research confirms that perceived outgroup threats challenging either the ingroup's dominant position in society, or the ingroup's cultural norms and beliefs, exacerbate negative outgroup attitudes and behaviors (Riek, Mania, \& Gaertner, 2006; Stephan \& Renfro, 2002), particularly among those who are most inclined to follow/defend mainstream social norms and dominant ideological systems; those higher in RWA or SDO (e.g., Asbrock, Sibley, \& Duckitt, 2010; Costello \& Hodson, 2011; Hodson, Hogg, \& MacInnis, 2009; McFarland, 2005).

Moreover, the stronger the perceived threat, the more RWAs and SDOs feel legitimized in defending dominant cultural attitudes and norms, which becomes expressed as biased outgroup attitudes and behaviors (Duckitt \& Sibley, 2010; Jost, Glaser, Kruglanski, \& Sulloway, 2003). Based on these findings, we argue that those higher in RWA or SDO are more likely to construe vegetarian and anti-speciesist ideologies as a threat to the dominant and traditional carnist ideology which, in turn, is expressed in greater acceptance of animal exploitation and more meat consumption. Hence, we hypothesized that perceived threats posed by vegetarianism challenging carnist ideology explain why both SDO and RWA express more accepting attitudes toward animal exploitation and consume more meat.

Second, exploiting animals and consuming meat symbolize and articulate underlying competitive-power motives to dominate over animals and support for inequality between humans and animals (Allen \& Ng, 2003; Ruby, 2012; Twigg, 1983). Costello and Hodson (2010, in press) demonstrated that endorsing hierarchy and inequality among human relations, expressed in term of SDO, predicts stronger beliefs that humans are distinct from and superior to animals. Along similar lines, this social dominance perspective can be broadened to explain dominance strivings over the natural environment more generally (Milfont, Richter, Sibley, Wilson, \& Fischer, 2013). Consistent with Social Dominance Theory (Sidanius \& Pratto, 1999), endorsing human supremacy beliefs can therefore represent a legitimizing myth 
preserving and justifying hierarchies between humans and animals (see also Joy, 2010). Theoretically, a "given belief...can be classified as a [legitimizing myth] if and only if it is found to have a mediational relationship between the desire for group-based social dominance on the one hand and support for [hierarchy enhancement or attenuation] on the other" (Sidanius \& Pratto, 1999, p. 48). For instance, both broad legitimizing myths such as modern or symbolic racism (Pratto et al., 1994; Sidanius \& Pratto, 1999) and more specific beliefs such as outgroup dehumanization (Costello \& Hodson, 2010) and cavalier humor beliefs (Hodson, Rush, \& MacInnis, 2010) have been identified as mediators between SDO and expressed outgroup bias. Such legitimizing myths typically promote rejection and exploitation of low-status groups (Pratto et al., 1994; Sidanius \& Pratto, 1999; see also Hodson et al., 2010; Sibley \& Duckitt, 2010), in our case non-human animals. Therefore, we hypothesized that, in addition to perceived vegetarianism threat, those higher in SDO are expected to feel more entitled to exploit animals and eat meat as a result of holding greater human supremacy beliefs. Evidence of such mediation would support a legitimizing myth account of animal exploitation and consumption.

\subsection{Present Research}

The current research integrated well-established insights from theorizing on intergroup threat and group-based dominance into a single model to investigate why right-wing adherents (i.e., those higher on SDO or RWA) are more favorable toward animal exploitation and consume more meat. Two studies tested the mediating role of ideology threat from vegetarianism and human supremacy beliefs. We expected that ideology threat would mediate the effects of both SDO and RWA, whereas human supremacy beliefs would mediate primarily SDO effects. Study 1 employed a heterogeneous sample of adults; Study 2 employed a community sample with larger sub-samples of non-omnivores, and also statistically controlled for hedonistic meat-consumption motivations. 


\section{Study 1}

\subsection{Method}

Respondents were 260 Dutch-speaking adults (58.5\% females; $98.5 \%$ Belgians; $M_{\text {age }}=$ 36.53 years, $S D=15.74$ ) completing all relevant measures of a questionnaire, recruited by political and social science undergraduates from a Belgian university. The majority $(69.6 \%)$ self-identified as meat eater/omnivore, $16.2 \%$ as omnivores trying to reduce meat consumption, $8.8 \%$ as semi-vegetarian (i.e., occasionally eating meat), $1.9 \%$ as pescatarian (i.e., eating (shell)fish but no meat), $3.5 \%$ as vegetarian, and $0 \%$ as vegan.

Except for meat-consumption items, responses were given on a 1 (strongly disagree) to 5 (strongly agree) scale. Respondents completed a shortened 8-item RWA scale $(\alpha=.82)$, e.g., "Obedience and respect for authority are the most important virtues children should learn" (Altemeyer, 1981), and a shortened 8-item SDO scale $(\alpha=.80)$, e.g., "Some groups of people are simply not the equals of others" (Pratto et al., 1994). Eight items assessed perceived vegetarianism threat $(\alpha=.90)$, e.g., "The rise of vegetarianism poses a threat to our country's cultural customs" (see Appendix). Human supremacy was assessed with six items $(\alpha=.89)$, e.g., "The life of an animal is just not of equal value as the life of a human being" (see Appendix). Eight items of the Animal Attitude Scale measured attitudes toward animal exploitation $(\alpha=.74)$, e.g., "The use of animals such as rabbits for testing the safety of cosmetics and household products is unnecessary and should be stopped" (reverse-scored) (Herzog, Betchard, \& Pittman, 1991). Higher scores indicated greater acceptance of animal exploitation. Meat consumption was measured with two items $(\alpha=.66)$ tapping frequency of eating (a) meat and (b) meat substitutes/vegetarian products (reversed scored); scales ranged from 1 (never) to 7 (every meal). Table 1 presents scale reliabilities, means, standard deviations and zero-order correlations. 
Table 1.

\begin{tabular}{|c|c|c|c|c|c|c|c|c|c|c|}
\hline \multirow[b]{2}{*}{ Measure } & \multirow[b]{2}{*}{ Study } & \multirow[b]{2}{*}{$\alpha$} & \multirow[b]{2}{*}{ Mean } & \multirow[b]{2}{*}{$S D$} & \multicolumn{6}{|c|}{ Correlations } \\
\hline & & & & & 2 & 3 & 4 & 5 & 6 & 7 \\
\hline \multirow[t]{2}{*}{ 1. RWA } & $\mathrm{S} 1$ & .82 & 2.73 & 0.77 & $.45^{* * *}$ & $.40^{* * *}$ & .03 & .10 & $.26^{* * *}$ & \\
\hline & $\mathrm{S} 2$ & .85 & 2.54 & 0.69 & $.47^{* * *}$ & $.40^{* * *}$ & $.14^{* *}$ & $.14^{* *}$ & $.25^{* * *}$ & $.16^{* * *}$ \\
\hline \multirow[t]{2}{*}{ 2. SDO } & $\mathrm{S} 1$ & .80 & 2.17 & 0.68 & & $.37^{* * *}$ & $.18^{* *}$ & $.34^{* * *}$ & $.28^{* * *}$ & \\
\hline & $\mathrm{S} 2$ & .83 & 2.02 & 0.63 & & $.39^{* * *}$ & $.26^{* * *}$ & $.27^{* * * *}$ & $.27^{* * *}$ & $.20^{* * * *}$ \\
\hline \multirow[t]{2}{*}{ 3. Vegetarianism threat } & $\mathrm{S} 1$ & .90 & 2.06 & 0.78 & & & $.18^{* *}$ & $.28^{* * *}$ & $.41^{* * *}$ & \\
\hline & $\mathrm{S} 2$ & .90 & 1.61 & 0.62 & & & $.30^{* * *}$ & $.44^{* * *}$ & $.52^{* * *}$ & $.42^{* * *}$ \\
\hline \multirow[t]{2}{*}{ 4. Human supremacy } & $\mathrm{S} 1$ & .89 & 3.08 & 0.97 & & & & $.54^{* * *}$ & $.34^{* * *}$ & \\
\hline & $\mathrm{S} 2$ & .90 & 2.56 & 0.87 & & & & $.58^{* * *}$ & $.42^{* * *}$ & $.39^{* * *}$ \\
\hline \multirow[t]{2}{*}{ 5. Animal exploitation } & $\mathrm{S} 1$ & .74 & 2.32 & 0.61 & & & & & $.38^{* * *}$ & \\
\hline & $\mathrm{S} 2$ & .75 & 1.97 & 0.56 & & & & & $.50^{* * *}$ & $.49^{* * *}$ \\
\hline \multirow[t]{2}{*}{ 6. Meat consumption } & $\mathrm{S} 1$ & .66 & 5.13 & 1.09 & & & & & & \\
\hline & $\mathrm{S} 2$ & .70 & 3.51 & 1.42 & & & & & & $.64^{* * * *}$ \\
\hline 7. Meat liking & $\mathrm{S} 2$ & .89 & 2.76 & 1.17 & & & & & & \\
\hline
\end{tabular}

Table 1. Means, standard deviations, and correlations between variables in Study 1 (S1) and Study 2 (S2). Note. ${ }^{*} p<.05 ;{ }^{* *} p<.01 ;{ }^{* * *} p<.001$

\subsection{Results}

To test our hypotheses, we conducted structural equation modeling (SEM) with latent variables in Mplus (version 7.1, Muthén \& Muthén, 1998-2013) to control for measurement error, using a robust maximum likelihood estimation. To smooth measurement error and maintain an adequate ratio of cases-to-parameters, we averaged item subsets into three parcels for each latent factors, except for the latent factor of meat consumption which was based on its two items. In advance of the model test, the expected correlations between the latent constructs (see Table 2) revealed that both SDO and RWA were significantly positively 
related to meat consumption. Furthermore, SDO (and to lesser degree RWA) positively predicted greater acceptance of animal exploitation.

Next, we tested the proposed model in which RWA and SDO predict meat consumption and attitudes toward animal exploitation via the hypothesized mediators vegetarianism threat and human supremacy beliefs. A fully-saturated model was tested, including all possible paths of the mediation model. This model supported our mediation hypotheses (see Figure 1).

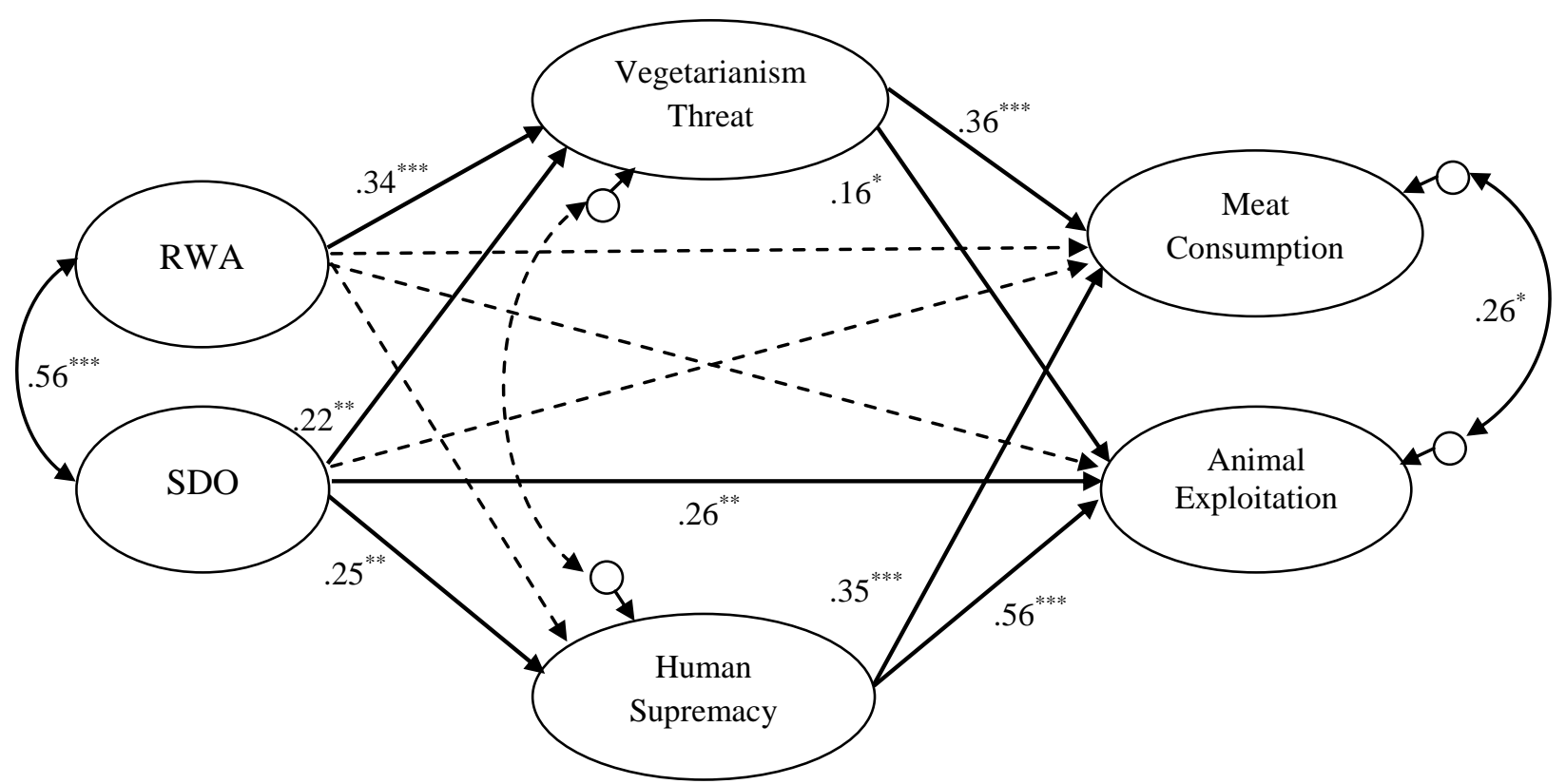

Figure 1. Mediation model showing standardized estimates of right-wing attitudes predicting attitudes toward animal exploitation and meat consumption through vegetarianism threat and human supremacy beliefs (Study 1). Note. ${ }^{*} p<.05 ;{ }^{* *} p<.01 ;{ }^{* * *} p<.001$. Dashed paths represent non-significant relationships Model fit: $\chi^{2}(104)=159.43, p<.001$; comparative fit index $=.97$; root-mean-square error of approximation $=.044$; standardized root-mean-square residual $=.041$.

As expected, both SDO and RWA positively predicted vegetarianism threat, and SDO (but not RWA) also predicted human supremacy beliefs. Furthermore, vegetarianism threat and human supremacy beliefs both positively predicted meat consumption and attitudes toward animal exploitation. Importantly, in the mediation model, the direct effects of RWA on meat consumption and attitudes toward animal exploitation were now non-significant (see also Table 2). SDO still exerted a significant (but attenuated) direct relationship with attitudes 
toward animal exploitation, reflecting partial mediation, yet no direct effect of SDO on meateating.

Table 2.

\begin{tabular}{|c|c|c|c|c|c|}
\hline \multirow[b]{2}{*}{ Predictor } & & \multicolumn{2}{|c|}{ Meat Consumption } & \multicolumn{2}{|c|}{ Animal Exploitation } \\
\hline & & Study 1 & Study 2 & Study 1 & Study 2 \\
\hline \multirow[t]{4}{*}{ SDO } & Latent correlation & $.36^{* * *}$ & $.29^{* * * *}$ & $.38^{* * *}$ & $.32^{* * *}$ \\
\hline & Direct effect & .04 & -.03 & $.26^{* *}$ & .07 \\
\hline & $\begin{array}{l}\text { Indirect effect via } \\
\text { Vegetarianism threat }\end{array}$ & $.08^{*}$ & $.05^{* *}$ & $.03^{\dagger}$ & $.05^{* *}$ \\
\hline & $\begin{array}{l}\text { Indirect effect via } \\
\text { Human supremacy }\end{array}$ & $.09^{*}$ & $.03^{*}$ & $.14^{* *}$ & $.11^{* * * *}$ \\
\hline \multirow[t]{4}{*}{ RWA } & Latent correlation & $.38^{* * *}$ & $.30^{* * *}$ & $.15^{*}$ & $.17^{* *}$ \\
\hline & Direct effect & .17 & $.09^{*}$ & -.11 & $-.11^{\dagger}$ \\
\hline & $\begin{array}{l}\text { Indirect effect via } \\
\text { Vegetarianism threat }\end{array}$ & $.12^{* *}$ & $.06^{* * *}$ & $.05^{\dagger}$ & $.06^{* * * *}$ \\
\hline & $\begin{array}{l}\text { Indirect effect via } \\
\text { Human supremacy }\end{array}$ & -.03 & .00 & -.04 & -.01 \\
\hline
\end{tabular}

$\overline{\text { Table 2. Effects of RWA and SDO on attitudes toward animal exploitation and meat }}$ consumption in Study 1 and Study 2. In Study 2 we controlled for meat liking. ${ }^{\dagger} p$ $<.10 ;{ }^{*} p<.05 ;{ }^{* *} p<.01 ;{ }^{* * *} p<.001$

Overall, RWA was significantly indirectly related to meat consumption whereas SDO was significantly indirectly related to both meat consumption and attitudes toward animal exploitation (for indirect effects see Table 2). The effect of RWA on meat consumption was fully mediated via vegetarianism threat, whereas the effect of SDO on meat consumption was fully mediated via both vegetarianism threat and human supremacy beliefs. The effect of SDO on attitudes toward animal exploitation was primarily channeled through human-supremacy (Table 2). The absence of direct effects on meat consumption in the mediation model 
indicates that vegetarianism threat and human supremacy largely account for why those higher in RWA or SDO consume more meat. Furthermore, human supremacy beliefs also explained, in a substantial way, why those higher in SDO are more favorable toward animal exploitation.

\section{Study 2}

In Study 2 we sought to replicate these findings and consider alternative explanations. Whereas Study 1 consisted predominantly of people self-identifying as 'pure' meat-eaters, somewhat limiting the range of meat consumption, in Study 2 we sampled greater proportions of respondents consuming less meat or no meat (e.g., self-identifying as pescatarian or vegetarian). Second, because high SDOs pursue hedonistic goals (Duriez \& Van Hiel, 2002), we assessed liking for meat as a control variable. As such, we can determine whether endorsing right-wing attitudes is related to more meat consumption merely because right-wing adherents generally like meat products in a hedonistic sense, or rather reflects the influence of hypothesized mediators (human dominance, non-carnist ideology threat).

\subsection{Method}

Respondents were 489 Belgian adults $\left(73.5 \%\right.$ females, $M_{\text {age }}=33.96$ years, $S D=$ 13.47) completing the entire survey, recruited by psychology undergraduates and through a Belgian organization promoting meat reduction; $24.7 \%$ meat-eaters/omnivores, $11.5 \%$ omnivores trying to reduce meat consumption, $18.8 \%$ semi-vegetarians, $9.8 \%$ pescatarians, $28.8 \%$ vegetarians, $7.0 \%$ vegans.

RWA $(\alpha=.85)$, SDO $(\alpha=.83)$, human supremacy beliefs $(\alpha=.90)$, vegetarianism threat $(\alpha=.90)$, attitudes toward animal exploitation $(\alpha=.75)$, and meat consumption $(\alpha=$ .70) were administered as per Study 1 (see descriptives in Table 1). We also administered three items $(\alpha=.89)$ on a 1 (strongly disagree) to 5 (strongly agree) scale assessing liking for meat's taste, look, and smell (e.g., "I like the taste of meat"). 


\subsection{Results}

We followed the same analytical procedures as in Study 1. Replicating Study 1, we found significant relationships between the latent factors of right-wing ideologies (SDO, RWA) on the one hand and meat consumption and attitudes toward animal exploitation on the other (see Table 1). Next, we tested the same model as in Study 1 but also included meatliking as a latent covariate (indicated by its items), set to predict both mediators and outcome measures. As such, we tested if the hypothesized model remained viable after controlling for basic meat-liking (see Figure 2). Although meat-liking significantly predicted all variables ( $p$ s $<.001)$, all hypothesized paths in the mediation model remained significant $(p s<.001)$.

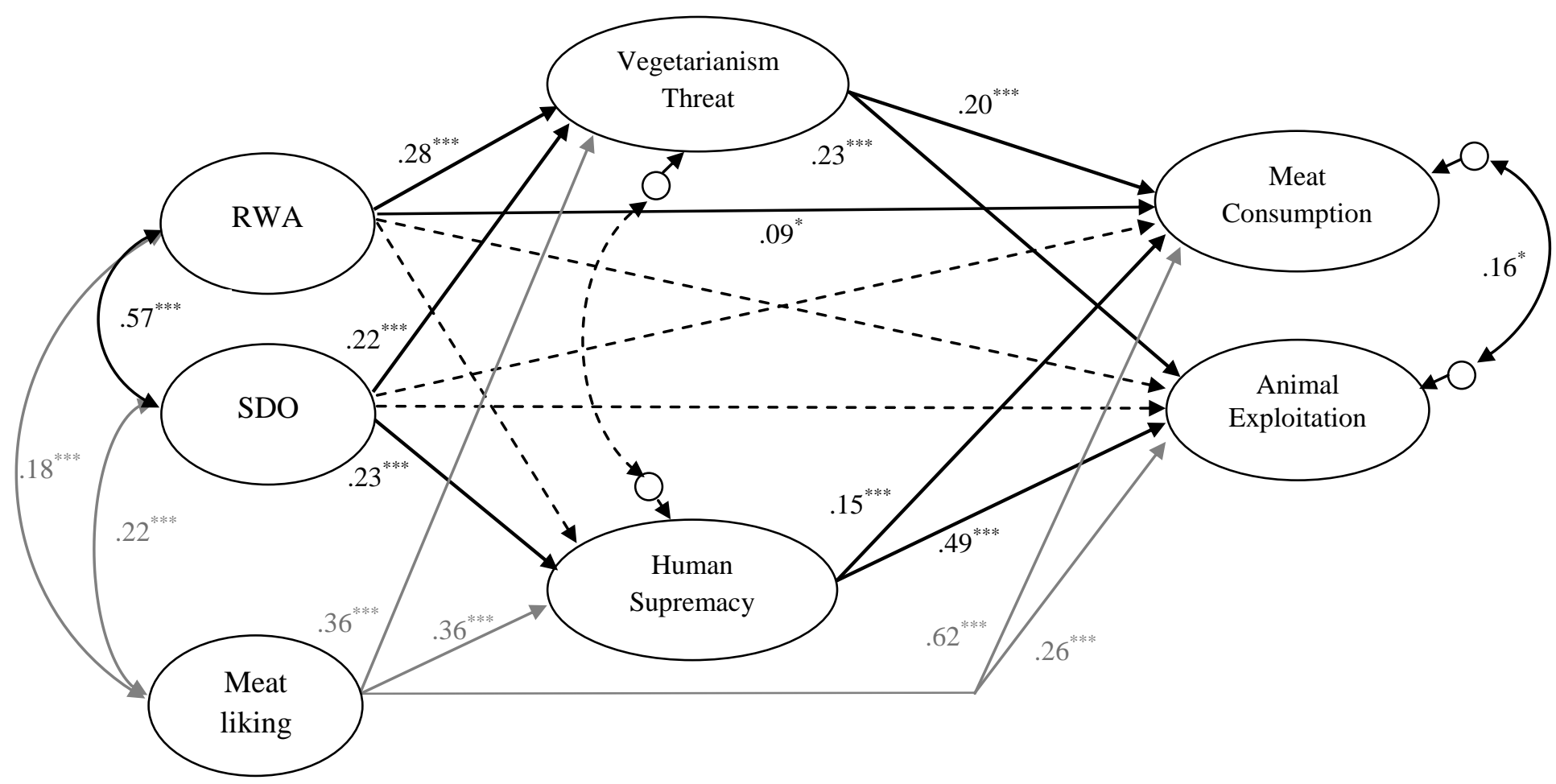

Figure 2. Mediation model (showing standardized estimates) of relationships between rightwing attitudes and attitudes toward animal exploitation and meat consumption through vegetarianism threat and human supremacy, while controlling for meat-liking (Study 2). Note. ${ }^{*} p<.05 ;^{* *} p<.01 ;{ }^{* * *} p<.001$. Dashed paths represent non-significant relationships. Model fit: $\chi^{2}(149)=307.24, p<.001$; comparative fit index $=.97$; root-mean-square error of approximation $=.047$; standardized root-mean-square residual $=.039$. 
Critically, the hypothesized indirect effects also remained significant after controlling for meat-liking (see Table 2). The effects of SDO and RWA on meat consumption and attitudes toward animal exploitation were significantly mediated via vegetarianism threat (for both SDO and RWA) and human supremacy beliefs (for SDO). In contrast to their zero-order relations (see Table 2), the direct effects of SDO and RWA on attitudes toward animal exploitation were non-significant in the mediation model. Likewise, the direct effect on meat consumption was non-significant for SDO, and clearly curbed (although significant) for RWA. Therefore, Study 2 demonstrates that, even after controlling for basic hedonistic meatliking, vegetarian ideology threat and human supremacy beliefs are critical variables in explaining why right-wing adherents are relatively more likely to accept animal exploitation and consume more meat.

\section{Discussion}

Those higher in RWA or SDO hold prejudiced attitudes against deviants and outgroups (e.g., immigrants) because they are seen as threatening the dominant culture and ideological system (e.g., Asbrock et al.2010; Dhont \& Van Hiel, 2011; Hodson et al., 2009; Kteilly, Ho, \& Sidanius, 2012). Only recently have researchers considered how dominanceideologies against human outgroups share commonalities with human-animal relations and exploitation (e.g., Costello \& Hodson, 2010, in press; Hodson \& Costello, 2012; Jackson, 2011; Plous, 2003). Across two community samples, we confirm that those higher (vs. lower) in RWA or SDO demonstrate greater acceptance of animal exploitation and greater animal consumption. More importantly, we reveal that right-wing ideologies predict animal exploitation and consumption through two psychological processes: (a) perceived threat that animal-rights ideologies pose to the dominant carnist ideology (for both SDO and RWA effects), and (b) belief in human superiority over animals (for SDO effects). These findings replicate across samples, and hold after controlling for hedonistic pleasure from eating meat 
(Study 2), itself a strong predictor $(r=.64)$ of meat-consumptive behavior. These results highlight critical individual differences between people concerning beliefs about group-based dominance and rights. Differences between those higher (vs. lower) in RWA or SDO in meateating behavior are clearly ideological in nature, referencing power, might, and greater "rights" over animals, plus an active push-back against movements advocating for the underpowered (i.e., non-human animals).

We asked why right-wing adherents exploit and consume animals more, making our mediation approach ideal. Future researchers could make salient human superiority over animals (see Costello \& Hodson, 2010) or heighten threat from system-change and pro-animal ideologies. Future researchers could also examine these patterns outside of European/Western contexts. Nonetheless, the present findings go theoretically beyond previous literature on the role of individual differences in intergroup relations, combining theorizing on intergroup threat (Stephan \& Stephan, 2000; Stephan \& Renfro, 2002) and group dominance (Pratto et al., 1994; Sidanius \& Pratto, 1999) into a single model in order to explain biased attitudes and group-based oppression regarding animals among high RWAs and SDOs. Furthermore, the results clarify that these theoretical frameworks are not limited to the psychology of human intergroup relations but can be generalized and also apply to the psychological study of human-animal relations. Our findings therefore contribute to a growing literature on similarities between human-human intergroup relations and human-animal relations (Hodson \& Costello, 2012; Plous, 2003). It is increasingly clear that constructs relevant to the former (e.g., right-wing ideologies) actually have much broader implications, proving meaningful predictors of the latter. Critically, human-animal relations are relevant to understanding human intergroup conflicts - after all, animalistically dehumanizing human outgroups facilitates prejudice and discrimination toward that group only because animals are devalued (Costello \& Hodson, 2010; Hodson \& Costello, 2012; Plous, 2003). Understanding the 
psychological underpinnings of human-animal relations is therefore relevant to animal welfare but also to human intergroup relations. 


\section{References}

Allen, M. W., \& Ng, S. H. (2003). Human values, utilitarian benefits and identification: The case of meat. European Journal of Social Psychology, 33, 37-56.

Allen, M. W., Wilson, M., Ng, S. H., \& Dunne, M. (2000). Values and beliefs of 979 vegetarians and omnivores. The Journal of Social Psychology, 140, 405-422.

Altemeyer, R. (1981). Right-wing authoritarianism. Winnipeg: University of Manitoba Press.

Altemeyer, R. (1998). The other "authoritarian personality". Advances in experimental social psychology, 30, 47-91.

Asbrock, F., Sibley, C. G., \& Duckitt, J. (2010). Right-wing authoritarianism and social dominance orientation and the dimensions of generalized prejudice: A longitudinal test. European Journal of Personality, 24, 324-340

Costello, K., \& Hodson, G. (2010). Exploring the roots of dehumanization: The role of animal-human similarity in promoting immigrant humanization. Group Processes \& Intergroup Relations, 13, 3-22.

Costello, K., \& Hodson, G. (2011). Social dominance-based threat reactions to immigrants in need of assistance. European Journal of Social Psychology, 41, 220-231.

Costello, K., \& Hodson, G. (in press). Explaining dehumanization among children: The interspecies model of prejudice. British Journal of Social Psychology.

Dhont, K., \& Van Hiel, A. (2011). Direct contact and authoritarianism as moderators between extended contact and reduced prejudice: Lower threat and greater trust as mediators. Group Processes \& Intergroup Relations, 14, 223-237.

Dietz, T., Frisch, A. S., Kalof, L., Stern, P. C., \& Guagnano, G. A. (1995). Values and vegetarianism. An exploratory analysis. Rural Sociology, 60, 533-542.

Duckitt, J. (2001). A dual-process cognitive-motivational theory of ideology and prejudice. Advances in Experimental Social Psychology, 33, 41-113. 
Duckitt, J., \& Sibley, C. G. (2010). Personality, ideology, prejudice, and politics: A dualprocess motivational model. Journal of Personality, 78, 1861-1894.

Duriez, B., \& Van Hiel, A. (2002). The march of modern fascism. A comparison of social dominance orientation and authoritarianism. Personality and Individual Differences, $32,1199-1213$.

Herzog, H. A., Betchard, N. S., \& Pittman, R. (1991). Gender, sex role identity and attitudes toward animals. Anthrozoos, 4, 184-191.

Hodson, G., \& Busseri, M.A. (2012). Bright minds and dark attitudes: Lower cognitive ability predicts greater prejudice through right-wing ideology and low intergroup contact. Psychological Science, 23, 187-195.

Hodson, G., \& Costello, K. (2012). The human cost of devaluing animals. New Scientist, $2895,34-35$.

Hodson, G., Hogg, S.M., \& MacInnis, C.C. (2009). The role of "dark personalities" (narcissism, Machiavellianism, psychopathy), Big Five personality factors, and ideology in explaining prejudice. Journal of Research in Personality, 43, 686-690.

Hodson, G., Rush, J., \& MacInnis, C.C. (2010). A “joke is just a joke” (except when it isn’t): Cavalier humor beliefs facilitate the expression of group dominance motives. Journal of Personality and Social Psychology, 99, 660-682.

Hyers, L. (2006). Myths used to legitimize the exploitation of animals: An application of social dominance theory. Anthrozoos, 19, 194-210.

Jackson, L. M. (2011). The psychology of prejudice: From attitudes to social action. APABooks.

Jost, J. T., Glaser, J., Kruglanski, A. W., \& Sulloway, F. (2003). Political conservatism as motivated social cognition. Psychological Bulletin, 129, 339-375. 
Joy, M. (2010). Why we love dogs, eat pigs, and wear cows: an introduction to carnism. San Francisco, CA: Conari Press.

Kteily, N. S., Ho, A., \& Sidanius, J. (2012). Hierarchy in the mind: The predictive power of social dominance orientation across social contexts and domains. Journal of Experimental Social Psychology, 48,543-549.

McFarland, S. M. (2005). On the eve of war: Authoritarianism, social dominance, and American students' attitudes toward attacking Iraq. Personality and Social Psychology Bulletin, 31, 360-367.

Milfont, T. S., Richter, I., Sibley, C. G., Wilson, M. S., \& Fischer, R. (2013). Environmental consequences of the desire to dominate and be superior. Personality and Social Psychological Bulletin, 39, 1127-1138.

Muthen, L. K., \& Muthen, B. O. (1998-2013). Mplus user's guide (seventh edition). Los Angeles, CA: Muthen and Muthen.

Plous, S. (2003). Is there such a thing as prejudice toward animals? In S. Plous (Ed.), Understanding prejudice and discrimination (pp. 509-528). New York: McGraw-Hill.

Pratto, F., Sidanius, J., Stallworth, L. M., \& Malle, B. F. (1994). Social Dominance Orientation: A personality variable predicting social and political attitudes. Journal of Personality and Social Psychology, 67, 741-763.

Riek, B. M., Mania, E.W., \& Gaertner, S. L. (2006). Intergroup threat and outgroup attitudes: A meta-analytic review. Personality and Social Psychology Review, 10, 336-353.

Roets, A., Van Hiel, A., \& Dhont, K. (2012). Is sexism a gender issue? A motivated social cognition perspective on men's and women's sexist attitudes toward the own and other gender. European Journal of Personality, 26, 350-359

Ruby, M. B. (2012). Vegetarianism. A blossoming field of study. Appetite, 58, 141-150. 
Sibley, C. G., \& Duckitt, J. (2010). The ideological legitimation of the status quo:

Longitudinal tests of a social dominance model. Political Psychology, 31, 109-137.

Stephan,W. G., \& Renfro, C. L. (2002). The role of threat in intergroup relations. In D. M.

Mackie, \& E. R. Smith (Eds.), From prejudice to intergroup emotions: Differentiated reactions to social groups (pp. 191-207). New York: Psychology Press.

Stephan, W. G., \& Stephan, C. W. (2000). An integrated threat theory of prejudice. In S. Oskamp (Ed.), Reducing prejudice and discrimination (pp. 23-46). Mahwah, N.J: Erlbaum.

Sidanius, J., \& Pratto, F. (1999). Social dominance: An intergroup theory of social hierarchy and oppression. Cambridge: Cambridge University Press.

Twigg, J. (1983). Vegetarianism and the meanings in meat. In A. Murcott (Ed.), The sociology of food and eating: Essays on the sociological significance of food. Aldershot: Gower. 


\section{Captions}

Table 1. Means, standard deviations, and correlations between variables in Study 1 (S1) and Study 2 (S2).

Table 2. Effects of RWA and SDO on attitudes toward animal exploitation and meat consumption in Study 1 and Study 2. In Study 2 we controlled for meat liking.

Figure 1. Mediation model showing standardized estimates of right-wing attitudes predicting attitudes toward animal exploitation and meat consumption through vegetarianism threat and human supremacy beliefs (Study 1). Note. ${ }^{*} p<.05 ;{ }^{* *} p<.01 ;{ }^{* * *} p<.001$. Dashed paths represent non-significant relationships. Model fit: $\chi^{2}(104)=159.43, p<.001$; comparative fit index $=.97$; root-mean-square error of approximation $=.044$; standardized root-mean-square residual $=.041$.

Figure 2. Mediation model (showing standardized estimates) of relationships between rightwing attitudes and attitudes toward animal exploitation and meat consumption through vegetarianism threat and human supremacy, while controlling for meat-liking (Study 2). Note. ${ }^{*} p<.05 ;{ }^{* *} p<.01 ;{ }^{* * *} p<.001$. Dashed paths represent non-significant relationships. Model fit: $\chi^{2}(149)=307.24, p<.001 ;$ comparative fit index $=.97$; root-mean-square error of approximation $=.047 ;$ standardized root-mean-square residual $=.039$. 


\section{Appendix}

Items of vegetarianism threat and human supremacy beliefs (translated from Dutch) used in

Study 1 and 2 ( 1 = strongly disagree to $5=$ strongly agree $)$.

\section{Vegetarianism Threat}

1. The rise of vegetarianism poses a threat to our country's cultural customs.

2. Important culinary traditions which are typical to our country starting to die out due to the rise of vegetarianism.

3. Eating meat is part of our cultural habits and identity and some people should be more respectful of that.

4. Vegetarians should have more respect for our traditional eating customs, which meat consumption is simply part of.

5. Important family traditions and celebrations are increasingly being ruined and disappearing because of the presence of vegetarians in certain families.

6. Vegetarianism has a negative influence on the [Belgian] economy.

7. The vegetarian movement is too involved in local and national politics.

8. Nowadays, when it comes to nutrition and meals, people listen too much to what a minority of vegetarians wants.

\section{Human Supremacy Beliefs}

1. The life of an animal is just not of equal value as the life of a human being

2. Animals are inferior to humans

3. There is nothing unusual at all in the fact that humans dominate other animal species

4. We should strive to more equality between humans and animals (Recoded item)

5. In an ideal world, humans and animals would be treated on an equal basis (Recoded item)

6. It is important that we treat other animal species more equally (Recoded item) 